\title{
Evaluation Research on Emergency Capability of Emergent Events in Chinses Coal Mine
}

\author{
Cheng-lin Miao ${ }^{1}$, Li-yan Sun ${ }^{1, *}$ and Li Yang ${ }^{2}$ \\ ${ }^{1}$ School of Economics and Management, Anhui University of Science and \\ Technology, Huainan City, Anhui Province, China, 232001 \\ ${ }^{2}$ School of Humanities and Social Sciences, Anhui University of Science and \\ Technology, Huainan City, Anhui Province, China, 232001 \\ 1chlmiao@163.com,sliydy@163.com \\ 2y321212@163.com
}

\begin{abstract}
The frequent occurrence of coal mine emergent events caused great impact on the social order and economic stability. In order to effectively prevent the occurrence of coal mine emergent events, it is necessary to focus on upgrading the level of emergency capability. This paper proposes the evaluation model of emergency capability of coal mine emergent events by the multistage fuzzy quality synthetic evaluation method. The evaluation weights are determined by AHP, the multistage fuzzy comprehensive appraisal on emergency capability is made by the fuzzy mathematics method, the rank status of emergency capability of coal mine emergent events is determined according to the empirical analysis results. Finally, an empirical analysis is made, the results of first grade fuzzy comprehensive evaluation show that emergency rescue capability is good and others are general, the results of second grade show that coal enterprises emergency capability is general, the average score is 74.445 less than 80 which indicates that the overall situation of emergency capability of coal mine emergent events is general.
\end{abstract}

Keywords: Emergency capability; Safety management; Coal mine emergent events; Multilevel fuzzy comprehensive evaluation

\section{Instruction}

Compared with general business, coal enterprises have complex production systems, multiple production processes, complex geological environment, poor production environmental conditions and other characteristics [1-4]. Coal enterprises prone to emergent events whose influence is relatively large range and destruction is more serious [5-7]. The urgent need for coal enterprises is to enhance emergency capability to respond to emergent events, so it is more important to analyze the current situation of emergency capability [8,9].

In response to emergent events, coal enterprises try to minimize the damage and losses caused by emergent events and can timely return to normal production, these are called to be coal enterprises emergency capabilities [10-13]. Coal mine emergent events are sudden and uncertain, but emergency capability runs through every stages of emergent events $[14,15]$. The aim of emergency capability is the prevention, control and elimination of emergent events. Therefore, improvement of emergency capability can effectively reduce property damage, personal injury and environmental damage extent caused by emergent events [16-18].

In order to evaluate emergency capability of coal mine emergent events, the paper proposes the evaluation model by the multistage fuzzy quality synthetic evaluation

\footnotetext{
${ }^{*}$ Corresponding Author
} 
method, determines the evaluation weights by AHP, utilizes the fuzzy mathematics method to carry on multistage fuzzy comprehensive appraisal, then determines the rank status. Finally, an empirical analysis is made to verify the validity and practicality of the evaluation model. Through evaluation on emergency capability of coal mine emergent events, we can determine the defects and shortcomings, and then develops the response measures, enhances the emergency capability level, so that the results can provide some reference for studying the state of emergency capability and improving the emergency capability of coal mine enterprises in China.

\section{Indicator System}

Coal enterprises emergency capability management is a dynamic and changing process, including the prevention, monitoring, control and recovery capability in every stage of emergent events [19-21]. The paper analyzes the main influencing factors of emergency capability of coal mine emergent events in every stage, constructs the evaluation indicator system according to the files of the National Coal Mine Safety Supervision Bureau and the relevant research results (showing in Table 1).

Table 1. Evaluation Indicator System of Emergency Capability

\begin{tabular}{|c|c|c|}
\hline $\begin{array}{l}\text { Target } \\
\text { layer }\end{array}$ & Primary indicators & Secondary indicators \\
\hline \multirow{21}{*}{ 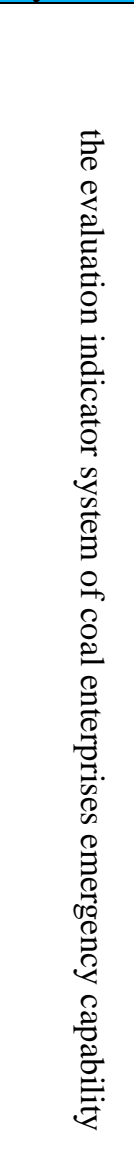 } & \multirow{4}{*}{ emergency monitoring capability $\mathrm{U}_{1}$} & monitoring and forecasting $\mathrm{U}_{11}$ \\
\hline & & emergency material support $U_{12}$ \\
\hline & & $\begin{array}{l}\text { emergency command and coordination } \\
\mathrm{U}_{13}\end{array}$ \\
\hline & & degree of hazard identification $\mathrm{U}_{14}$ \\
\hline & \multirow{3}{*}{ emergency response capability $\mathrm{U}_{2}$} & recognition judgment $U_{21}$ \\
\hline & & degree of actual rescue $U_{22}$ \\
\hline & & degree of emergency response $U_{23}$ \\
\hline & \multirow{4}{*}{ enterprise recovery capability $\mathrm{U}_{3}$} & restore production level $\mathrm{U}_{31}$ \\
\hline & & accident analysis level $\mathrm{U}_{32}$ \\
\hline & & plan amendment $\mathrm{U}_{33}$ \\
\hline & & emergency relief agencies perfection $\mathrm{U}_{34}$ \\
\hline & \multirow{5}{*}{ emergency rescue capability $\mathrm{U}_{4}$} & effective relief of rescue personnel $\mathrm{U}_{41}$ \\
\hline & & effective work of rescue equipment $\mathrm{U}_{42}$ \\
\hline & & medical supplement $\mathrm{U}_{43}$ \\
\hline & & rescue techniques $\mathrm{U}_{44}$ \\
\hline & & situation control $\mathrm{U}_{45}$ \\
\hline & \multirow{3}{*}{ emergency command capability $\mathrm{U}_{5}$} & $\begin{array}{l}\text { rescue command's correct and efficient } \\
\mathrm{U}_{51}\end{array}$ \\
\hline & & rescue resource allocation $\mathrm{U}_{52}$ \\
\hline & & rescue command methodical $\mathrm{U}_{53}$ \\
\hline & \multirow{2}{*}{ resource readiness capability $\mathrm{U}_{6}$} & rescue equipment integrity $\mathrm{U}_{61}$ \\
\hline & & rescue team effectiveness $\mathrm{U}_{62}$ \\
\hline \multirow[t]{3}{*}{$\subset$} & \multirow{3}{*}{$\begin{array}{l}\text { organization management capability } \\
\qquad U_{7}\end{array}$} & rules and regulations implementation $\mathrm{U}_{71}$ \\
\hline & & rational organization $\mathrm{U}_{72}$ \\
\hline & & personnel management efficiency $\mathrm{U}_{73}$ \\
\hline
\end{tabular}




\section{Evaluation Process}

(1) Evaluation indicator system is an ordinary collection composed by the factors affecting the evaluation object which is expressed by the capital letters $U$, namely: $U=\left\{U_{1}, U_{2}, \cdots\right\}$.

This paper divides affecting factors into seven categories, so $U=\left\{U_{1}, U_{2}, \cdots, U_{7}\right\}$, each subset $U_{i}=\left\{u_{i 1}, u_{i 2}, \cdots, u_{i n}\right\}, u_{i j}(i=1,2, \cdots, 7 ; j=1,2, \cdots, n)$ denotes $j$ th factor in $i$ th subset.

(2) In order to reflect the importance of each factor, each factor should be given appropriate weight. All weights are subjectively determined based on the needs of the practical problems or in accordance with the degree of membership [22-23].

If same factors have different weights, the evaluation outcome will be different. Weights are determined by the evaluation team's experience and discussion or AHP.

According to the importance degree of these seven categories evaluation indicators, the corresponding weights are given on each category. $A_{i}(i=1,2, \cdots, 7)$ is the weight of $i$ th factor $U_{i}$, the weights set of evaluation indicators is $A=\left(A_{1}, A_{2}, \cdots, A_{7}\right)$.

For each category evaluation indicators, weight is given according to its importance degree. $a_{i j}(i=1,2, \cdots, 7 ; j=1,2, \cdots, n)$ is the weight of $j$ th indicator $u_{i j}$ in $i$ th category, their weights set is $A_{i}=\left(a_{i 1}, a_{i 2}, \cdots, a_{i n}\right)(i=1,2, \cdots, 7)$.

(3) Determining the judgment matrix $R_{i}$ composed of single factor evaluation, then getting the first evaluation vector. The comment set is $V=\left\{V_{1}\right.$ (excellent), $V_{2}$ (good), $V_{3}$ (fair), $V_{4}$ (relatively poor), $V_{5}$ (poor) $\}$. Fuzzy matrix $R_{i}$ which is from sub factor set $U_{i}$ to comment $\operatorname{set} V_{i}$ is shown as following:

$$
R_{i}=\left(\begin{array}{cccc}
r_{11} & r_{12} & \cdots & r_{1 n} \\
r_{21} & r_{22} & \cdots & r_{2 n} \\
\vdots & \vdots & \ddots & \vdots \\
r_{n 1} & r_{n 2} & \cdots & r_{n n}
\end{array}\right)
$$

The first evaluation vector is gotten through the synthesis operation of fuzzy matrix, $B_{i}=A_{i} \times R_{i}=\left(B_{i 1}, B_{i 2}, \cdots, B_{i n}\right), \quad(i=1,2, \cdots, 7)$.

(4) The alternative sets $V$ are a collection composed by the evaluation results, each element is denoted as $v_{i}(i=1,2, \cdots, m)$. The purpose of fuzzy comprehensive evaluation is to choose the best evaluation result from the alternative sets.

If there are $p$ evaluation results, alternative sets can be expressed by $V=\left\{v_{1}, v_{2}, \cdots, v_{p}\right\}, \quad v_{i}(i=1,2, \cdots, 7)$ denotes $P$ th evaluation outcome.

(5) Multilevel fuzzy comprehensive evaluation starts from the bottom ( $j$ th layer), the results aren't calculated upward layer by layer until the final remark set $B$ is gotten. The evaluation results in $j$ th layer is the factor's membership in $j$ th layer [24].

Single index evaluation matrix $R$ of evaluation indicator system $U$ is gotten as following:

$$
R=\left(\begin{array}{c}
B_{1} \\
\vdots \\
B_{7}
\end{array}\right)=\left(\begin{array}{cccc}
b_{11} & b_{12} & \cdots & b_{15} \\
\vdots & \vdots & \ddots & \vdots \\
b_{71} & b_{72} & \cdots & b_{75}
\end{array}\right)
$$

The second evaluation vector $B=A \times R=\left(B_{1}, B_{2}, \cdots, B_{5}\right)$ is gotten, the normalized 


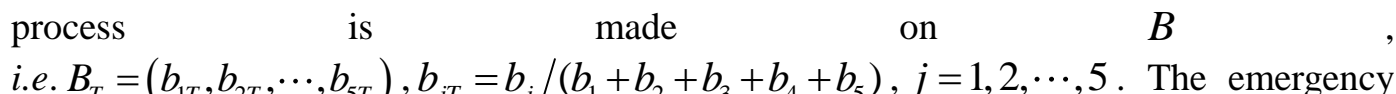
capability level of coal mine emergent events is obtained according to the principle of maximum membership.

\section{Empirical Analysis}

\subsection{Evaluation Indicators' Weight}

Taking some coal enterprise in Anhui Province in China as an example to carry on the empirical analysis. An expert group is composed by seven coal mine managers and three emergency management experts. The group scores on the relative importance of various evaluation indicators and their subsets, then the paper makes the weighted average to get the judgment matrix. Feature vector and characteristic root are respectively calculated, and then consistency test is made.

The judgment matrix of evaluation indicator system $U$ and all subsets' weights are shown as following:

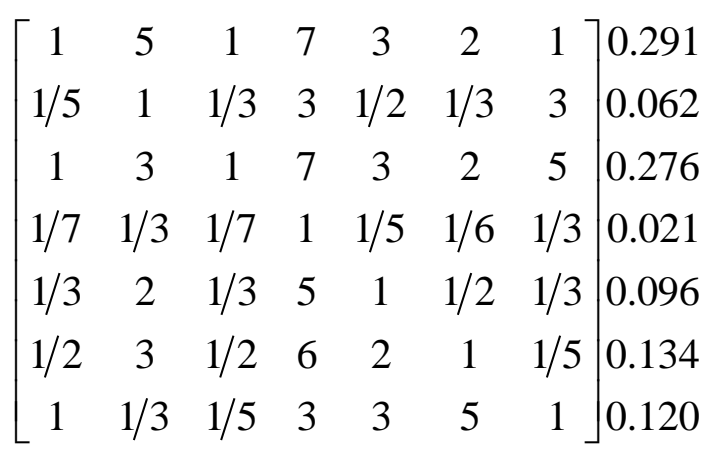

The consistency test is passed, i.e. $C R=0.020<0.1$

The judgment matrix of emergency monitoring capability $U_{l}$ and the weights of its factors are gotten as following:

$$
\left[\begin{array}{cccc|c}
1 & 3 & 1 / 2 & 1 / 3 \\
1 / 3 & 1 & 1 / 5 & 1 / 6 & 0.165 \\
2 & 5 & 1 & 1 / 2 & 0.064 \\
3 & 6 & 2 & 1
\end{array}\right] 0.293
$$

The consistency test is passed, i.e. $C R=0.013<0.1$

The judgment matrix of emergency response capability $U_{2}$ and the weights of its factors are gotten as following:

$$
\left(\begin{array}{ccc|c}
1 & 3 & 1 / 3 & 0.258 \\
1 / 3 & 1 & 1 / 5 & 0.105 \\
3 & 5 & 1
\end{array}\right) 0.637
$$

The consistency test is passed, i.e. $C R=0.033<0.1$

The judgment matrix of enterprise recovery capability $U_{3}$ and the weights of its factors are gotten as following: 


$$
\left(\begin{array}{cccc|c}
1 & 1 / 3 & 1 / 4 & 1 / 6 & 0.062 \\
3 & 1 & 1 / 3 & 1 / 7 & 0.111 \\
4 & 3 & 1 & 1 / 2 & 0.282 \\
6 & 7 & 2 & 1 & 0.545
\end{array}\right.
$$

The consistency test is passed, i.e. $C R=0.055<0.1$

The judgment matrix of emergency rescue capability $U_{4}$ and the weights of its factors are gotten as following:

$$
\left(\begin{array}{ccccc|c}
1 & 1 / 5 & 1 / 3 & 1 / 2 & 1 / 9 & 0.045 \\
5 & 1 & 3 & 2 & 1 / 4 & 0.208 \\
3 & 1 / 3 & 1 & 2 & 1 / 5 & 0.116 \\
2 & 1 / 2 & 1 / 2 & 1 & 1 / 5 & 0.088 \\
9 & 4 & 5 & 5 & 1
\end{array}\right) 0.543
$$

The consistency test is passed, i.e. $C R=0.037<0.1$

The judgment matrix of emergency command capability $U_{5}$ and the weights of its factors are gotten as following:

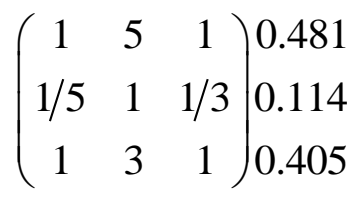

The consistency test is passed, i.e. $C R=0.025<0.1$

The judgment matrix of resource readiness capability $U_{6}$ and the weights of its factors are gotten as following:

$$
\left(\begin{array}{cc}
1 & 1 / 3 \\
3 & 1
\end{array}\right) 0.250
$$

The consistency test is passed, i.e. $C R=0.000<0.1$

The judgment matrix of organization management capability $U_{7}$ and the weights of its factors are gotten as following:

$$
\left(\begin{array}{ccc|c}
1 & 3 & 5 & 0.637 \\
1 / 3 & 1 & 3 & 0.105 \\
1 / 5 & 1 / 3 & 1 & 0.258
\end{array}\right.
$$

The consistency test is passed, i.e. $C R=0.033<0.1$

\subsection{Comprehensive Evaluation Results}

Experts score each evaluation indicator based on their experience. The reviews set is $\mathrm{V}$ $=\{$ excellent, good, fair, relatively poor, poor $\}$. The membership of each indicator is gotten by the expert opinion, all that constitute the membership matrix.

(1) First grade fuzzy comprehensive evaluation 


$$
\begin{gathered}
B_{1}=A_{1} \times R_{1}=(0.165,0.064,0.293,0.479) \times\left(\begin{array}{ccccc}
0 & 0.1 & 0.5 & 0.3 & 0.1 \\
0.2 & 0.2 & 0.2 & 0.4 & 0 \\
0.1 & 0.4 & 0.2 & 0.2 & 0.1 \\
0.2 & 0.2 & 0.1 & 0.2 & 0.3
\end{array}\right) \\
=(0.137,0.242,0.202,0.230,0.189)
\end{gathered}
$$

Similarly, $B_{2}, B_{3}, B_{4}, B_{5}, B_{6}, B_{7}$ can be calculated.

$$
\text { So, } R=\left(\begin{array}{lllll}
0.137 & 0.242 & 0.202 & 0.230 & 0.189 \\
0.122 & 0.241 & 0.290 & 0.403 & 0.015 \\
0.137 & 0.153 & 0.462 & 0.283 & 0.165 \\
0.258 & 0.364 & 0.263 & 0.306 & 0.059 \\
0.206 & 0.360 & 0.375 & 0.215 & 0.074 \\
0.135 & 0.307 & 0.360 & 0.217 & 0.069 \\
0.162 & 0.264 & 0.374 & 0.324 & 0.043
\end{array}\right)
$$

(2) Second grade fuzzy comprehensive evaluation

$$
B=A \times R=(0.148,0.243,0.339,0.265,0.124)
$$

Where, $A=(0.291,0.062,0.276,0.021,0.096,0.134,0.120)$.

(3) Evaluation results

The quantitative treatment on the comments is made, the grade standard of coal enterprises emergency capability is determined, i.e. poor $(50,60)$, relatively poor $(60,70)$, general $(70,80)$, good $(80,90)$, excellent $(90,100)$.

$$
\begin{aligned}
& S_{H}=\frac{1}{0.148+0.243+0.381+0.279+0.124} \times(0.148,0.243,0.381,0.279,0.124) \times(59,69,79,89,99)^{T}=78.780 \\
& S_{M}= \frac{1}{0.148+0.243+0.381+0.279+0.124} \times(0.148,0.243,0.381,0.279,0.124) \times(55,65,75,85,95)^{T}=74.779 \\
& S_{L}= \frac{1}{0.148+0.243+0.381+0.279+0.124} \times(0.148,0.243,0.381,0.279,0.124) \times(50,60,70,80,90)^{T}=69.781 \\
& \text { The average is } 74.445 .
\end{aligned}
$$

(4) the evaluation results analysis

According to the results of first grade fuzzy comprehensive evaluation, $13.7 \%$ of the experts believe that emergency monitoring capability is excellent, $24.2 \%$ of the experts believe that it is good, $20.2 \%$ of the experts believe that it is general, $23.0 \%$ of experts believe that it is relatively poor, $18.9 \%$ of the experts believe that it is poor. Emergency monitoring capability is general according to the maximum membership principle.

Similarly, emergency response capability is general, enterprise recovery capability is general, emergency rescue capability is good, emergency command capability is general, resource readiness capability is general, organization management capability is general.

According to the results of second grade fuzzy comprehensive evaluation, $14.8 \%$ of the experts believe that coal enterprises emergency capability is excellent, $24.3 \%$ of the experts believe that it is good, $33.9 \%$ of the experts believe that it is general, $26.5 \%$ of experts believe that it is relatively poor, $12.4 \%$ of the experts believe that it is poor. Coal enterprises emergency capability is general according to the maximum membership principle.

Finally, after the quantification of comments, the highest score of coal enterprises emergency capability is 78.780 which less than 80 , the lowest score is 69.781 which less than 70 , the average score is 74.445 , so that emergency capability of those coal enterprises emergent events is general. 


\section{Conclusion}

After determining the evaluation indicators of emergency capability of coal mine emergent events, this paper proposes the theoretical evaluation process based on the multilevel fuzzy comprehensive evaluation method. An empirical analysis is made and the results show that the average score is 74.445 less than 80 , which indicates its situation is general; emergency monitoring capability is the best and its weight value is 0.291, emergency rescue capability is the worst and its weight value is only 0.021 .

It is necessary to seize and embark on improving the key factors. However, partial improvement could not make direct impact on promoting emergency capability and the result even might be counterproductive; therefore, it is important to accurately recognize critical factors. The evaluation on emergency capability just is means, the aim is to build evaluation indicator system, and identify deficiencies and problems, and suggest the improvements for these issues, and constantly enhance the emergency capability to respond to emergent events, and strive to minimize the damage.

Coal production conditions is more complex, it is more susceptible to emergent events, so that coal mining enterprises should establish and improve the emergency management system. After evaluating emergency capability of coal mine emergent events, the next step is how to better build the enterprise emergency management system. The building of emergency management system is more complex, that is to further research.

\section{Acknowledgments}

This paper is supported by the following funds. National Natural Science Foundation of China (71503003, 71371014); Anhui Province Natural Science Foundation of China (1508085QG147, 1708085QG166); Anhui Province Philosophy and Social Science Planning Foundation of China (AHSKY2015D78, AHSKQ2016D26); Anhui Province Soft Science Foundation of China (1502052055); Humanities and Social Sciences Foundation of Education Department, Anhui Province, China (SK2016A0291).

\section{References}

[1] H. Chen, Q. Feng and J. Cao, "Rent-seeking mechanism for safety supervision in the Chinese coal industry based on a tripartite game model", Energy Policy, vol. 72, (2014), pp. 140-145.

[2] F. Geng and J. H. Saleh, "Challenging the emerging narrative: Critical examination of coalmining safety in China, and recommendations for tackling mining hazards", Safety Science, vol. 75, (2015), pp. 36-48.

[3] D. Pohl, A. Bouchachia and H. Hellwagner, "Online indexing and clustering of social media data for emergency management”, Neuro- computing, vol. 172, (2016), pp. 168-179.

[4] Y. Li, Y. Hu and X. Zhang, "An evidential DEMATEL method to identify critical success factors in emergency management", Applied Soft Computing, vol. 22, (2014), pp. 504-510.

[5] J. Chen, L. Ma, C. Wang, H. Zhang and M. Ha, "Comprehensive evaluation model for coal mine safety based on uncertain random variables", Safety Science, vol. 68, (2014), pp. 146-152.

[6] D. Ergu, G. Kou, Y. Peng and M. Zhang, "Estimating the missing values for the incomplete decision matrix and consistency optimization in emergency management", Applied Mathematical Modelling, vol. 40, no. 1, (2016), pp. 254-267.

[7] S. Alves and M. Fernandez, "A Framework for the Analysis of Access Control Policies with Emergency Management", Electronic Notes in Theoretical Computer Science, vol. 312, (2015), pp. 89-105.

[8] Q. Liu, X. Li and M. Hassall, "Evolutionary game analysis and stability control scenarios of coal mine safety inspection system in China based on system dynamics", Safety Science, vol. 80, (2015), pp. 13-22.

[9] F. Wex, G. Schryen, S. Feuerriegel and D. Neumann, "Emergency response in natural disaster management: Allocation and scheduling of rescue units", European Journal of Operational Research, vol. 235, no. 3, (2014), pp. 697-708.

[10] K. A. Lachlan, P. R. Spence and X. Lin, "Social media and crisis management: CERC, search strategies, and Twitter content", Computers in Human Behavior, vol. 54, no. 1, (2016), pp. 647-652.

[11] J. Kim, S. Y. Park, K. Ahn and J. E. Yang, "iROCS: Integrated accident management framework for coping with beyond-design-basis external events”, Nuclear Engineering and Design, vol. 298, (2016), pp. $1-13$.

[12] P. Tang and Q. Shen, "Decision-making model to generate novel emergency response plans for 
improving coordination during large-scale emergencies”, Knowledge- Based Systems, vol. 90, (2015), pp. 111-128.

[13] D. Khayal, R. Pradhananga, S. Pokharel and F. Mutlu, "A model for planning locations of temporary distribution facilities for emergency response", Socio-Economic Planning Sciences, vol. 52, (2015), pp. 22-30.

[14] N. Li, B. B. Gerber and L. Soibelman, "Comparative assessment of an indoor localization framework for building emergency response", Automation in Construction, vol. 57, (2015), pp. 42-54.

[15] D. Liu, X. Xiao, H. Li and W. Wang, "Historical evolution and benefit-cost explanation of periodical fluctuation in coal mine safety supervision: An evolutionary game analysis framework", European Journal of Operational Research, vol. 243, no. 3, (2015), pp. 974-984.

[16] S. Xiaoyan and X. Zhongpeng, "Application of Man-machine-environment System Engineering in Coal Mines Safety Management”, Procedia Engineering, vol. 84, (2014), pp. 87-92.

[17] L. Jin, W. Jiong and D. Yang, "A Simulation Study for Emergency/Disaster Management by Applying Complex Networks Theory”, Journal of Applied Research and Technology, vol.12, no.2, (2014), pp. 223-229.

[18] L. Wang, Z. X. Zhang and Y. M. Wang, "A prospect theory-based interval dynamic reference point method for emergency decision making", Expert Systems with Applications, vol. 42, no. 23, (2015), pp. 9379-9388.

[19] W. Lirong, J. Zhongan and C. Weimin, "Major accident analysis and prevention of coal mines in China from the year of 1949 to 2009", Mining Science and Technology (China), vol. 21, no. 5, (2011), pp. 693-699.

[20] S. Curnin, C. Owen, D. Paton and B. Brooks, "A theoretical framework for negotiating the path of emergency management multi-agency coordination”, Applied Ergonomics, vol. 47, (2015), pp. 300-307.

[21] X. H. Xu, Z. J. Du and X. H. Chen, "Consensus model for multi-criteria large-group emergency decision making considering non-cooperative behaviors and minority opinions", Decision Support Systems, vol. 79, (2015), pp. 150-160.

[22] Q. Tao, S. Yuhang and L. Zhenwen, "Study on the Index System of Safety Evaluation in Coal Mine based on AHP”, Morden Mining, no. 5, (2010), pp. 70-72.

[23] L. Jie, "The preliminary evaluation of coal mine safety based on AHP", Journal of Shanxi Datong University (Natural Science Edition), no. 3, (2009), pp. 66-69.

[24] J. Lu and Z. Xia, "Financial Early-warning for Real Estate Enterprises Based on Multilevel Fuzzy Comprehensive Evaluation", Journal of Jilin Institute of Architecture \& Civil Engineering, vol. 29, no. 21, (2012), pp. 93-95.

\section{Authors}

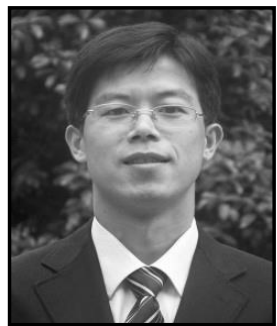

Cheng-lin Miao, (1980-), male, Doctor, Associate Professor, Research direction: safety management, innovation management; presided over 5 fund projects, published more than 40 papers in academic journals both at home and abroad. Postal address: School of Economics and Management, Anhui University of Science and Technology, Huainan City, Anhui Province, China, 232001, E-mail: chlmiao@163.com.

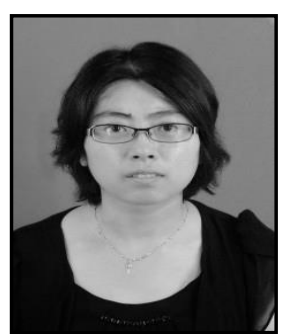

Li-yan Sun, (1982-), female, Master, Lecturer, Research direction: safety management; presided over 4 fund projects, published more than 20 papers in academic journals both at home and abroad. Postal address: School of Economics and Management, Anhui University of Science and Technology, Huainan City, Anhui Province, China, 232001, E-mail: chlmiao@163.com. 